\title{
Microglial MAC1 receptor and PI3K are essential in mediating $\beta$-amyloid peptide-induced microglial activation and subsequent neurotoxicity
}

\author{
Dan Zhang ${ }^{1,2^{*}}$, Xiaoming Hu ${ }^{1,3}$, Li Qian ${ }^{1,4}$, Shih-Heng Chen ${ }^{1,5}$, Hui Zhou', Belinda Wilson ${ }^{1}$, David S Miller ${ }^{1}$, \\ Jau-Shyong Hong ${ }^{1}$
}

\begin{abstract}
Background: $\beta$-Amyloid peptide $(A \beta)$ is a major protein in the brain associated with Alzheimer's and Parkinson's diseases. The purpose of this study was to investigate the role of macrophage antigen-1 (MAC1) receptor, an integrin scavenger receptor in microglia, and subsequent signaling events in mediating A $\beta$-induced neurotoxicity. We have previously reported that NADPH oxidase (PHOX) on microglia and superoxide produced by PHOX are critical for $A \beta$-induced loss of dopaminergic neurons. However, the upstream signaling pathway of superoxide production remains unclear.
\end{abstract}

Methods: For the in vitro study, mesencephalic neuron-glia cultures and microglia-enriched cultures from mice deficient in the MAC1 receptor $\left(\mathrm{MACl}^{-1}\right.$ ) and wild type controls were used to investigate the role of MAC1 receptor in A $\beta$-induced neurotoxicity and the role of phosphoinositide-3 kinase (PI3K) in the signal pathway between MAC1 receptor and PHOX. For the in vivo study, $A \beta$ was injected into the substantia nigra of $\mathrm{MAC1}^{-1-}$ mice and wild type mice to confirm the role of MAC1 receptor.

Results: We found that A $\beta$-induced activation of microglia, activation of PHOX, generation of superoxide and other reactive oxygen species, and loss of dopaminergic neurons were decreased in $\mathrm{MACl}^{-1}$ cultures compared to $\mathrm{MACl}^{+/+}$cultures. In $\mathrm{MAC1}^{-1-}$ mice, dopaminergic neuron loss in response to $A \beta$ injection into the substantia nigra was reduced relative to $\mathrm{MACl}^{+/+}$mice. Thus, MAC1 receptor-mediated PHOX activation and increased superoxide production are associated with A $\beta$-induced neurotoxicity. PI3K activation was one downstream step in MAC1 signaling to PHOX and played an important role in $A \beta$-induced neurotoxicity. In microglia-enriched cultures from $\mathrm{MAC1}^{-1-}$ mice, $A \beta$-induced activation of PI3K (phosphorylation of target proteins and $\mathrm{PIP}_{3}$ production) was reduced relative to $\mathrm{MACl}^{+/+}$cultures.

Conclusions: Taken together, our data demonstrate that $A \beta$ activates MAC1 receptor to increase the activity of PI3K, which in turn phosphorylates p47 $7^{\text {phox }}$, triggers the translocation of cytosolic subunits of PHOX to microglia membrane, increases PHOX activation and the subsequent production of superoxide and causes neurotoxicity.

\section{Background}

$\beta$-Amyloid peptide $(A \beta)$ has been reported to exist in numerous diseases such as Alzheimer's disease (AD), Parkinson's disease (PD), age-related macular degeneration and Lewy body disease with dementia

\footnotetext{
* Correspondence: danzhang@imm.ac.cn

'Laboratory of Pharmacology, National Institute of Environmental Health

Sciences, National Institutes of Health, Research Triangle Park, NC 27709, USA Full list of author information is available at the end of the article
}

[1-3]. Immunohistochemical analysis reveals that $A \beta$ deposits in the brain are surrounded by and infiltrated by activated microglia $[4,5]$, suggesting that microglia are involved in the pathogenesis of amyloid-related diseases.

The major purpose of this paper was to study the molecular signaling events mediating the neurotoxicity of $A \beta$. The essential role of microglia in mediating $\mathrm{A} \beta$-elicited neurotoxicity was extensively compared in

\section{Biomed Central}

(C) 2011 Zhang et al; licensee BioMed Central Ltd. This is an Open Access article distributed under the terms of the Creative Commons Attribution License (http://creativecommons.org/licenses/by/2.0), which permits unrestricted use, distribution, and reproduction in any medium, provided the original work is properly cited. 
both cortical and midbrain cultures in our previously published paper and the results showed that they were qualitatively similar [6]. This similarity in $A \beta$-elicited toxicity in both cortical vs. midbrain cultures was further demonstrated in the present study. Thus, we believe that the signaling pathway mediating $A \beta$-elicited neurotoxicity obtained from midbrain cultures should be applicable to the cortical cultures. The main reason for using midbrain dopamine neuron-microglia cultures for the mechanistic studies in this paper was due to its unique features: 1) the high density of microglia (about 5 times more than cortical cultures) and 2) higher sensitivity of dopamine neurons to oxidative damage in the midbrain cultures. For these reasons, midbrain culture has been widely used for studying the role of microglia in oxidative insult-related neurotoxicity. For the same reason, we selected substantia nigra $(\mathrm{SN})$ in the in vivo study so that we could quantitatively measure specific damage of dopamine neurons in a much precise and reproducible manner.

The present study is concerned with how $A \beta$ signaling leads to the activation of NADPH oxidase (PHOX). We tested the hypothesis that signaling is mediated by macrophage antigen complex-1 (MAC1) receptor. MAC1 (integrin CD11b/CD18 receptor) is both an adhesion molecule and a pattern recognition receptor that has long been recognized to regulate diverse functions involved in adhesion, migration, phagocytosis and chemotaxis $[7,8]$. MAC1 was previously identified as a TLR4-independent receptor for lipopolysaccharide (LPS) in phagocytes [9]. MAC1 is elevated in the brains of post mortem $\mathrm{AD}$ patients [10] and in the 1-methyl-4phenyl-1,2,3,6-tetrahydropyridine (MPTP) animal model of PD [11], suggesting a role for MAC1 in neurodegeneration. MAC1 receptor is essential for phagocytosis of multiple compounds and the activation of phagocytes in response to a diverse set of stimuli $[12,13]$. MAC1 is also associated with respiratory burst in neutrophils [8], suggesting that it may be a potential source of microglia-derived oxidative stress. It has also been reported that MAC1 plays a role in PHOX activation in response to oxidative insults $[8,12,14]$. Other evidence suggests that MAC1 occupancy is capable of triggering the transcription factor nuclear factor $-\kappa \mathrm{B}(\mathrm{NF}-\kappa \mathrm{B})$ signaling pathway and the subsequent production of inflammatory factors $[15,16]$. There is increasing evidence that pattern recognition receptors (i.e. TLR4, scavenger receptors, and MAC1) associated with phagocytes are critical in mediating neurotoxic effects. Recently, we reported that microglial MAC1 receptor plays a critical role in mediating neurotoxicity induced by LPS, $\alpha$-synuclein and MPTP [17-19].
Here, we implicate the MAC1 receptor in $\mathrm{A} \beta$-induced microglial activation, and $A \beta$-induced neurotoxicity, in vitro and in vivo. We show that MAC1 signals through Phosphoinositide-3 kinase (PI3K) to activate PHOXmediated superoxide generation and neurotoxicity.

\section{Methods \\ Reagents}

A $\beta(1-42)$ was purchased from the American Peptide Company (Sunnyvale, CA, USA). WST-1 was purchased from Dojindo Laboratories (Gaithersburg, MD). Cell culture ingredients were obtained from Invitrogen (Carlsbad, CA). [ $\left.{ }^{3} \mathrm{H}\right]$ dopamine $(30 \mathrm{Ci} / \mathrm{mmol})$ and $\left[2,3-{ }^{3} \mathrm{H}\right] \gamma$-Aminobutyric acid (GABA) $(81 \mathrm{Ci} / \mathrm{mmol})$ was purchased from Perkin Elmer Life Sciences (Boston, MA). The polyclonal antibody against tyrosine hydroxylase $(\mathrm{TH})$ was a kind gift from Dr. John Reinhard of GlaxoSmithKline (Research Triangle Park, NC). Monoclonal antibody against the F4/80 was obtained from Serotec (Raleigh, NC). Polyclonal antibody against Iba1 was obtained from Wako Chemicals USA, Inc. (Richmond, VA). Vectastain avidin-biotinylated enzyme complex, biotinylated horse anti-mouse and goat anti-rabbit secondary antibodies were purchased from Vector Laboratories (Burlingame, CA). Rabbit anti-p47 $7^{\text {phox }}$ antibody was obtained from Upstate (Lake Placid, NY). FITC-conjugated goat anti-rabbit IgG antibody was obtained from Jackson ImmunoResearch Laboratories (West Grove, PA). Rabbit anti-GAPDH, rabbit anti-AKT (phosphor S473) antibodies were obtained from Abcam (Cambridge, MA). Mouse antigp91 ${ }^{\text {phox }}$ antibody was purchased from BD Transduction Laboratories (San Jose, CA). Rabbit anti-PI3K p110 antibody was purchased from Santa Cruz Biotechnology, Inc. FITCconjugated anti phosphoinositide $(3,4,5)$ bisphosphate ( $\left.\mathrm{PIP}_{3}\right)$ antibody was purchased from Echelon Bioscience (Salt Lake City, UT, USA). All other reagents were purchased from Sigma-Aldrich (St. Louis, MO).

\section{Animals}


background) and C57BL/6J ( $\left.\mathrm{MAC1}^{+/+}\right)$mice were purchased from Jackson Laboratories (Bar Harbor, Maine). All the animals were housed in a specific pathogen free facility, and fed a standard laboratory chow ad libitum. Housing, breeding and experimental use of the animals were performed in strict accordance with the National Institutes of Heath guidelines.

\section{A $\beta$ preparation}

The peptide (1-42) was reconstituted in PBS, $\mathrm{pH} 7.4$ at a concentration of $100 \mu \mathrm{M}$. Aliquots of stocks were incubated at $37^{\circ} \mathrm{C}$ for 3 days to form amyloid fibrils. 


\section{$A \beta$ injection in vivo}

Male $\mathrm{MAC1}^{-/-}$and $\mathrm{MAC}^{+/+}$mice were anesthetized with sodium pentobarbital $(80 \mathrm{mg} / \mathrm{kg}$ ) and positioned in a small animal stereotaxic apparatus. Injection of $A \beta$ into SN was made using the flowing stereotaxic coordinates, measured from bregma: $3.0 \mathrm{~mm}$ posterior, 1.7 $\mathrm{mm}$ lateral, and $4.7 \mathrm{~mm}$ ventral. $\mathrm{A} \beta(2 \mu \mathrm{g}$ in $1 \mu \mathrm{l}$ of saline) was injected into the right side of the $\mathrm{SN}$ over a period of $2 \mathrm{~min}$, and the injection needle was kept in place for 2 min after the injection. A control injection of saline alone was made into the left side of SN under the conditions described above. Ten animals were used for each strain.

\section{Analysis of neurotoxicity}

For the in vivo study, 24 consecutive coronal brain slices (35- $\mu \mathrm{m}$ thickness), which encompassed the entire $\mathrm{SN}$, compact part, were collected. A normal distribution of the number of TH-positive neurons in the SN, compact part was constructed based on the counts of 24 slices from $\mathrm{MAC1}^{-/-}$mice and $\mathrm{MAC1}^{+/+}$mice. The distribution curves from these two noninjected groups superimpose and show no difference in number and shape of the curves. Eight evenly spaced brain slices from saline or A $\beta$-injected animals were immunostained with an antibody against $\mathrm{TH}$ and subsequently TH-positive neurons were counted. The distribution of the cell numbers from each animal was matched with the normal distribution curve to correct for errors resulting from the cutting of the brain. Three individuals performed counting in a doubleblind manner. Conclusions were drawn only when the difference was within $5 \%$.

\section{Primary mesencephalic mixed neuron-glia cultures}

Primary mesencephalic mixed neuron-glia cultures were prepared from the brains of embryonic day $13 \pm 0.5$ $\mathrm{MAC}^{+/+}$and $\mathrm{MAC1}^{-/-}$mice as previously described [20]. Briefly, the ventral midbrain portion of the embryonic brain was dissected under a microscope and kept in cold minimum essential medium (MEM). Mesencephalic tissues were isolated and dissociated with gentle mechanical trituration. Cells were diluted to $1.5 \times$ $10^{6} / \mathrm{ml}$ in maintenance medium (MEM supplemented with $10 \%$ heat-inactivated fetal bovine serum (FBS), 10\% heat-inactivated horse serum, $1 \mathrm{~g} / \mathrm{L}$ glucose, $2 \mathrm{mM} \mathrm{L-}$ glutamine, $1 \mathrm{mM}$ sodium pyruvate, $100 \mu \mathrm{M}$ non-essential amino acids, $50 \mathrm{U} / \mathrm{ml}$ penicillin, and $50 \mu \mathrm{g} / \mathrm{ml}$ streptomycinand) and seeded in 24-well culture plates pre-coated with poly-D-lysine $(20 \mu \mathrm{g} / \mathrm{ml})$. Plates were maintained at $37^{\circ} \mathrm{C}$ in a humidified atmosphere of $5 \%$ $\mathrm{CO}_{2}$ and $95 \%$ air. Seven day-old cultures were used for treatment. The composition of the cells at the time of treatment was approximately $48 \%$ astrocytes, $11 \%$ microglia, $40 \%$ neurons with $1 \%$ of which being $\mathrm{TH}$ positive neurons.

\section{Primary mesencephalic microglia-depleted cultures}

Twenty-four hours after seeding the cells, $1 \mathrm{mM}$ L-leucine methyl ester was added to the culture. Two days later, cultures were changed back to maintenance medium and were used for treatment 7 days after initial seeding. The cultures stained with Iba-1 antibody showed less than $0.1 \%$ microglia.

\section{Primary cortical neuron-glia culture}

Mouse cortical neuron-glia were prepared from the brains of embryonic day $16 \pm 0.5 \mathrm{MAC}^{+/+}$and $\mathrm{MAC1}^{-/-}$mice. The cortex was dissociated by mild mechanical trituration in MEM. After pelleting by centrifugation, cells were resuspended and plated $\left(5 \times 10^{5} /\right.$ well) in 24-well culture plates precoated with poly dlysine. Cultures were maintained in the same medium as described above for mesencephalic neuron-glia cultures. Seven-day cultures were used for treatment. The composition of cortical neuron-glia cultures was determined by immunostaining with antibodies against Neu-N and Iba-1. Cortical neuron-glia cultures contained $60 \% \mathrm{Neu}-$ N-IR neurons and 3.1\% Iba-1-IR microglia. The remaining cells were presumed to be astroglia.

\section{Primary microglia-enriched cultures}

Primary microglia-enriched cultures were prepared from the whole brains of 1 -day-old $\mathrm{MAC1}^{+/+}$and $\mathrm{MAC1}^{-1-}$ pups as described previously [20]. Briefly, brain tissues were triturated after removing the meninges and blood vessels. Cells were seeded at $5 \times 10^{7}$ in a $150 \mathrm{~cm}^{3}$ cultures flask with Dulbecco's modified Eagle's medium/ F12 (DMEM/F12) containing 10\% heat-inactivated FBS, $2 \mathrm{mM}$ L-glutamine, $1 \mathrm{mM}$ sodium pyruvate, $100 \mu \mathrm{M}$ non-essential amino acids, $50 \mathrm{U} / \mathrm{ml}$ penicillin and 50 $\mu \mathrm{g} / \mathrm{ml}$ streptomycin, $\mathrm{pH}=7.2$. After a confluent monolayer of glia cells had been obtained (12-14 days after initial seeding), microglia were shaken off, collected and seeded. The purity of microglia is greater than $98 \%$.

\section{Uptake assays for $\left[{ }^{3} \mathrm{H}\right]$ dopamine or $\left[{ }^{3} \mathrm{H}\right] \mathrm{GABA}$}

Cells were incubated for $15 \mathrm{~min}$ at $37^{\circ} \mathrm{C}$ with $1 \mu \mathrm{m}\left[{ }^{3} \mathrm{H}\right]$ DA or $5 \mu \mathrm{m}\left[{ }^{3} \mathrm{H}\right] \mathrm{GABA}$ in Krebs-Ringer buffer $(16 \mathrm{~mm}$ $\mathrm{NaH}_{2} \mathrm{PO}_{4}, 16 \mathrm{~mm} \mathrm{Na} \mathrm{HPO}_{4}, 119 \mathrm{~mm} \mathrm{NaCl}, 4.7 \mathrm{~mm}$ $\mathrm{KCl}, 1.2 \mathrm{~mm} \mathrm{MgSO}_{4}, 1.3 \mathrm{~mm}$ EDTA, pH 7.4). Non-specific uptake was blocked by $10 \mu \mathrm{m}$ mazindol for dopamine uptake, or $10 \mu \mathrm{m} \mathrm{NO}-711$ and $1 \mathrm{~mm} \beta$-alanine for GABA uptake. After washing the cells three times with ice-cold Krebs-Ringer buffer $(1 \mathrm{ml} /$ well) and lysing with $1 \mathrm{~N} \mathrm{NaOH}(0.5 \mathrm{ml} /$ well $)$, the lysate was mixed with 15 $\mathrm{mL}$ scintillation fluid and radioactivity was determined with a liquid scintillation counter. The specific $\left[{ }^{3} \mathrm{H}\right]$ 
dopamine or $\left[{ }^{3} \mathrm{H}\right]$ GABA uptake was calculated by subtracting the amount of radioactivity obtained in the presence of mazindol or NO-711 and $\beta$-alanine from that obtained in the absence of mazindol or NO-711 and $\beta$-alanine.

\section{Immunostaining}

Immunostaining was performed as described previously [20]. Dopaminergic neurons were stained with the antibody against TH (1:5000). Microglia were stained with the antibody raised against F4/80 (1:20) or Iba-1 (1:1000). In brief, brain sections or $3.7 \%$ formaldehyde fixed cultures were treated with $1 \%$ hydrogen peroxide followed by sequential incubation with blocking solution (PBS containing 1\% BSA, 0.4\% Triton-X 100 and 4\% appropriate serum), primary antibody, biotinylated secondary antibody, and Vectastain $\mathrm{ABC}$ reagents. After washing, the bound complex was visualized by incubating cells with 3,3'-diaminobenzidine and urea-hydrogen peroxide tablets dissolved in water. Color development was terminated by removal of the reagents and washing the cultures with PBS. Images of in vitro cultures or brain staining were recorded with an inverted microscope (Nikon, Tokyo, Japan) or Zeiss microscope (Zeiss, Germany), respectively, connected to a charge-coupled device camera (DAGE-MTI, Michigan City, IN, USA) operated with the MetaMorph software (Universal Imaging Corporation, Downingtown, PA, USA).

\section{Superoxide assay}

The extracellular superoxide production was determined by measuring the superoxide dismutase (SOD)-inhibitable reduction of tetrazolium salt, WST-1 as described before [20] with modifications. Primary microglial enriched cultures grown in 96-well plates were treated with $A \beta$ or vehicle in $150 \mu \mathrm{l}$ of phenol red-free treatment medium. At $10 \mathrm{~min}$ after treatment, $50 \mu \mathrm{l}$ of WST-1 $(1 \mathrm{mM})$ in phenol red-free treatment medium, with or without SOD (600 units $/ \mathrm{ml})$, was added. The absorbance at $450 \mathrm{~nm}$ was read immediately with a Spectra Max Plus microtiter plate spectrophotometer (Molecular Devices, Sunnyvale, CA). For the superoxide assay using microglia-enriched culture, cells were plated at $1 \times 10^{5} /$ well in 96 -well plate and incubated at $37^{\circ} \mathrm{C}$ in a humidified atmosphere of $5 \% \mathrm{CO}_{2}$ and $95 \%$ air for 12 hours. The cells were washed twice and left in $100 \mu \mathrm{l}$ HBSS. Fifty $\mu \mathrm{l}$ HBSS, PMA or A $\beta$ were added. Then 50 $\mu \mathrm{l}$ of WST-1 (1 mM) in HBSS, with or without SOD (600 units $/ \mathrm{ml}$ ), was added. The absorbance at $450 \mathrm{~nm}$ was read immediately.

\section{Confocal microscopy}

Enriched microglial cells from mice were seeded in dishes at $5 \times 10^{4}$ cells/well and treated with $\mathrm{A} \beta$ for 10 min. Cells were fixed with $3.7 \%$ paraformaldehyde in PBS for $10 \mathrm{~min}$. After washing with PBS, cells were incubated with rabbit polyclonal antibody against $\mathrm{PIP}_{3}$ $(0.5 \mu \mathrm{g} / \mathrm{ml})$. Cells were then washed and incubated with FITC-conjugated goat anti-rabbit antibody. Focal planes spaced at $0.4 \mu \mathrm{m}$ intervals were imaged with a Zeiss 510 laser scanning confocal microscope (63X PlanApo 1.4 numerical aperture objective) equipped with LSM510 digital imaging software. Intracellular reactive oxygen species (iROS) were assessed as follows. Enriched microglial cells from mice were seeded in dishes at $5 \times 10^{4}$ cells/well and were incubated with $1 \times$ HBSS containing $5 \mu \mathrm{M}$ dichlorodihydrofluorescein diacetate (DCFDA) in the dark for 1 hour. Then cells were treated with $A \beta$ for $10 \mathrm{~min}$. Fluorescent images were captured using Zeiss 510 laser scanning confocal microscope.

\section{Cell extract}

Whole cell lysates from neuron-glia cultures were prepared with lysis buffer (Cell Signaling, Danvers, MA). Subcellular fractionation was performed. For subcellular fractions, microglia cells were lysed in hypotonic lysis buffer ( 1 mM EGTA, 1 mM EDTA, $10 \mathrm{mM} \beta$-glycerophosphate, $10 \mathrm{mM} \mathrm{NaF}, 1 \mathrm{mM}$ sodium orthovanadate, $2 \mathrm{mM} \mathrm{MgCl}_{2}, 10 \mathrm{mM}$ dithiothreitol, $1 \mathrm{mM}$ phenylmethylsulfonyl fluoride, and $10 \mu \mathrm{g} / \mathrm{ml}$ each of leupeptin, aprotinin, and pepstatin A), incubated on ice for $30 \mathrm{~min}$, and then subjected to Dounce homogenization (20-25 stokes, tight pestle A). The lysates were loaded onto a sucrose gradient in lysis buffer (final $0.5 \mathrm{M}$ ) and centrifuged at $1,600 \times \mathrm{g}$ for $15 \mathrm{~min}$. The supernatant above the sucrose gradient was used as the cytosolic fraction after centrifugation at $150,000 \times g$ for $30 \mathrm{~min}$. The pellets were solubilized in $1 \%$ Nonidet P-40 hypotonic lysis buffer and were used as membranous fraction.

\section{Western blot analysis}

Equal amounts of protein $(40 \mu \mathrm{g} / \mathrm{lane})$ were separated by $4-12 \%$ Bis-Tris-polyacrylamide electrophoresis gel and transferred to polyvinylidene difluoride membranes (Novex, San Diego, CA). Membranes were blocked with $5 \%$ nonfat milk and incubated with primary antibody (rabbit anti-p47 ${ }^{\text {phox }}$ antibody (1:2000), rabbit antiGAPDH (1:2000), mouse anti-gp91 ${ }^{\text {phox }}(1: 2000)$ or rabbit anti-Iba-1 (1:3000)) overnight at $4^{\circ} \mathrm{C}$. Membrane was then incubated with horseradish peroxidase-linked antirabbit or mouse IgG (1:3000) for $1 \mathrm{~h}$ at $25^{\circ} \mathrm{C}$. ECL Plus reagents (GE Healthcare, Little Chalfont, Buckinghamshire, UK) were used for detection.

\section{Statistical analysis}

The data were expressed as mean \pm SEM. Statistical significance between two groups was assessed with an analysis of variance followed by Student's $t$-test or 
nonparametric statistics. Statistical significance between multiple groups was performed using a one- or two-way analysis of variance (ANOVA). When ANOVA showed a significant difference, an LSD multiple comparisons post-hoc test was performed. A value of $\mathrm{p}<0.05$ was considered statistically significant.

\section{Results}

A $\beta$-induced dopaminergic and GABAergic neurotoxicity in neuron-glia cultures was attenuated with the absence of MAC1

To investigate the role of MAC1 in $\mathrm{A} \beta$-induced neurotoxicity, mesencephalic neuron-glia cultures prepared from $\mathrm{MAC1}^{+/+}$and $\mathrm{MAC1}^{-/-}$mice were treated with vehicle (controls) or $0.5,1$ or $2 \mu \mathrm{M} A \beta$. Dopaminergic neurotoxicity was assessed by dopamine uptake assay and cell number count/morphological analysis of immunostained TH-positive neurons. A $\beta$ exposure caused concentration-dependent decreases in $\left[{ }^{3} \mathrm{H}\right]$ dopamine uptake (Figure 1A) and the number of $\mathrm{TH}$-positive neurons (Figure 1B) in cultures from $\mathrm{MAC1}^{+/+}$and $\mathrm{MAC1}^{-1-}$ mice. For both measurements, decreases were significantly less in the $\mathrm{MAC1}^{-1-}$ cultures. Morphological analysis showed that $\mathrm{TH}$-positive neurons in the $\mathrm{A} \beta$ treated $\mathrm{MAC1}^{+/+}$cultures (Figure 1C) displayed much shorter and less elaborate neurites compared with those

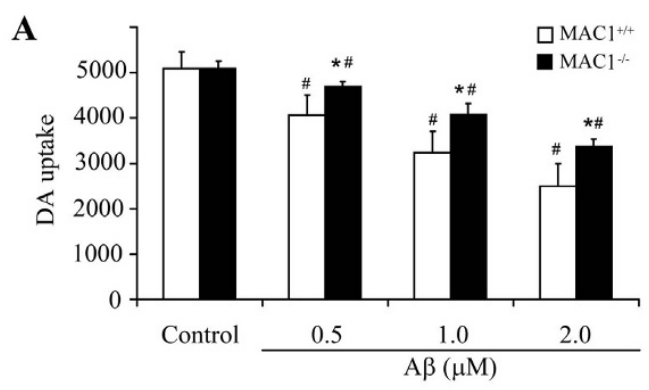

D



B
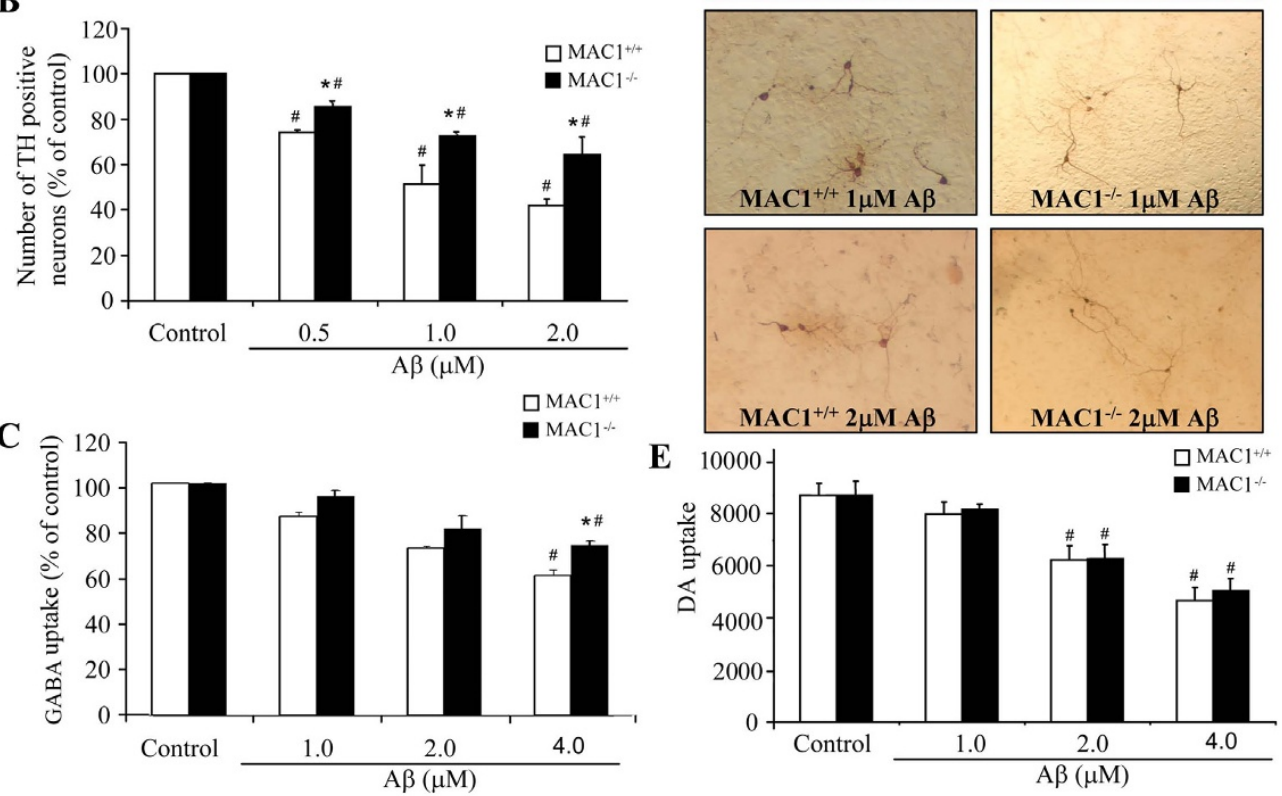

Figure 1 Absence of MAC1 attenuates $A \beta$-induced dopaminergic and GABAergic neurotoxicity in neuron-glia cultures. Mice (MAC $1^{+/+}$ and $\mathrm{MACl}^{-1}$ ) mesencephalic neuron-glia cultures in 24-well plates were treated with vehicle medium (control group) or $0.5 \mu \mathrm{M}, 1.0 \mu \mathrm{M}$ and 2.0 $\mu \mathrm{M} A \beta$ for 7 days. (A) A $\beta$-induced dopaminergic neurotoxicity was quantified by $\left[{ }^{3} \mathrm{H}\right]$ dopamine uptake assay. (B) Numbers of TH-positive cells remaining in the neuron-glia cultures after vehicle or $A \beta$ treatment. (D) Representative light microscopic images are shown for TH-positive neurons treated with vehicle or A $\beta$. Scale bar: $100 \mu \mathrm{m}$. (C) Mice (MAC1 ${ }^{+/+}$and $\mathrm{MAC}^{-1-}$ ) cortical neuron-glia cultures in $24-$ well plates were treated with vehicle or $1.0 \mu \mathrm{M}, 2.0 \mu \mathrm{M}$ and $4.0 \mu \mathrm{M}$ A $\beta$ for 7 days. A $\beta$-induced GABAergic neurotoxicity was quantified by [ ${ }^{3} \mathrm{H}$ ] GABA uptake assay. (E) Mice $\left(\mathrm{MACl}^{+/+}\right.$and $\mathrm{MAC1}^{-1}$ ) mesencephalic microglia-depleted cultures in 24-well plates were treated with vehicle medium (control group) or $1.0 \mu \mathrm{M}, 2.0 \mu \mathrm{M}$ and $4.0 \mu \mathrm{M}$ A $\beta$ for 7 days. A $\beta$-induced dopaminergic neurotoxicity was quantified by [ ${ }^{3} \mathrm{H}$ ] dopamine uptake assay. Results are from four independent experiments. \#: $\mathrm{p}<0.05$ compared with corresponding vehicle-treated controls. *: $\mathrm{p}<0.05$ compared with MAC ${ }^{+/+}$ cultures after same treatments. 
from $\mathrm{MAC}^{-1-}$ cultures. We also tested $\mathrm{A} \beta$-induced GABAergic neurotoxicity in cortical neuron-glia cultures. We found that $A \beta$ exerted a less potent reduction in GABA uptake in cortical neuron-glia cultures than DA uptake in mesencephalic neuron-glia cultures (Figure 1D). Because there are less microglia presented in cortical neuron-glia cultures than in mesencephalic neuron-glia cultures (about 3\% to 10\%), these results indicate that the presence of glia might potentiate the toxic effect of $A \beta$ and that is the reason that we used mesencephalic cultures for the rest of the study. Besides, we found no difference in $A \beta$-induced neurotoxicity in microglia-depleted cultures prepared from $\mathrm{MAC1}^{+/+}$ and $\mathrm{MAC1}^{-1-}$ mice (Figure 1E), confirming the role of microglial MAC1 in the different dopaminergic neurotoxicity of $A \beta$ that we observed in neuron-glia cultures.

\section{MAC1 is necessary for $A \beta$-induced microglial activation}

After demonstrating the important role of MAC1 in $A \beta$-induced neurotoxicity, we continued to investigate whether MAC1 expression affects $A \beta$-induced microglial activation. The total microglial number in the cultures from $\mathrm{MACl}^{+/+}$and $\mathrm{MACl}^{-/-}$mice are comparable (data not shown). Activation of microglia was assessed using $\mathrm{F} 4 / 80$ immunostaining in $\mathrm{MAC1}^{+/+}$and $\mathrm{MAC1}^{-/-}$neuron-glia cultures following exposure to $A \beta$. One day after treatment with $A \beta$, numerous activated microglia, characterized by intensified F4/80 staining and enlarged cell size, were distributed throughout the $\mathrm{MAC1}^{+/+}$culture (Figure $2 \mathrm{~A}$ ); $\mathrm{MAC1}^{+/+}$cultures contained a mixture of process-bearing ramified microglia and process-free amoeboid-like microglia. With $2 \mu \mathrm{M} \mathrm{A} \beta, \mathrm{MAC1}^{+/+}$cultures exhibited more F4/80-positive cells that appeared to be fully activated microglia with an amoeboid and condensed morphology. In cultures from $\mathrm{MAC1}^{-1-}$ mice, $\mathrm{A} \beta$ induced activation of microglia was noticeably less pronounced (Figure 2A). Western blots using antibody for Iba-1, a widely used marker for microglial activation, showed elevated Iba- 1 expression in $\mathrm{A} \beta$-treated $\mathrm{MAC}^{+/+}$ cultures but not in $\mathrm{MACl}^{-1-}$ cultures (Figure 2B and 2C).

\section{$\mathrm{MAC1}^{-1-}$ mice exhibit reduced $A \beta$-induced nigral dopamine neurotoxicity and microglial activation in vivo}

To determine the role of MAC1 in A $\beta$-induced DA neurotoxicity in vivo, we stereotaxically injected $\mathrm{A} \beta(2 \mu \mathrm{g}$ in $1 \mu \mathrm{l}$ of saline) into the substantia nigra (SN) of $\mathrm{MAC1}^{+/+}$
A
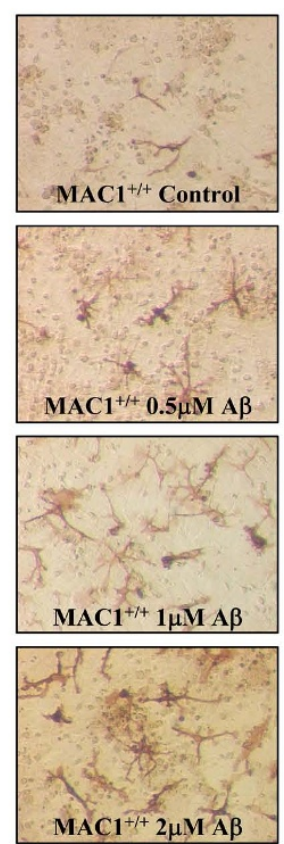


B



GAPDH



C

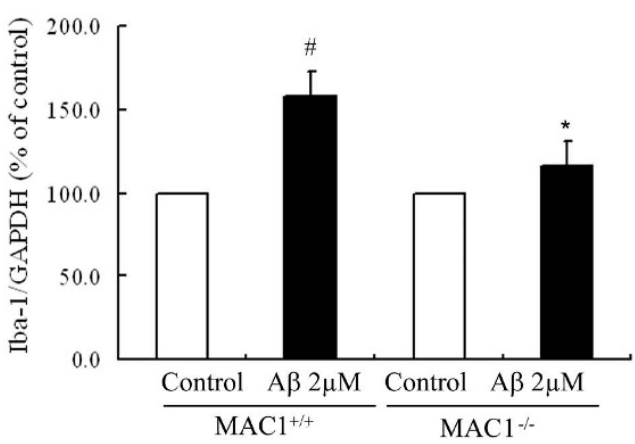

Figure 2 MAC1 is necessary for $\mathbf{A} \boldsymbol{\beta}$-induced microglial activation. Mesencephalic neuron-glia cultures from MAC $1^{+/+}$and $M A C 1^{-/}$mice were treated with vehicle medium (control group) or A $\beta$ for 2 days. (A) Cultures were fixed after treatments. Microglia were visualized by immunostaining of the F4/80 antigen, a microglial marker. The images presented are representative of three independent experiments. Scale bar: $50 \mu \mathrm{m}$. (B) Western blot analysis of microglial activation. Cell lysates of cultures from MAC $1^{+/+}$and MAC1 $1^{-/-}$mice were prepared 2 days after vehicle or $2.0 \mu \mathrm{M} \mathrm{A \beta}$ treatment and immunoblot analysis was performed for the measurement of Iba1 antigen. GAPDH was used as loading control. (C) The ratio of densitometry values of Iba1 and GAPDH was analyzed and normalized to respective control. Results are presented as mean \pm SEM for


same treatments. 
and $\mathrm{MAC1}^{-1-}$ mice. Seven days later, the brains were removed, and coronal sections through the nigral complex were immunostained with an antibody against tyrosine hydroxylase $(\mathrm{TH})$, a marker for dopaminergic neurons. Although TH-positive neuron counts were comparable in the saline-injected sides of $\mathrm{MACl}^{+/+}$mice and $\mathrm{MAC1}^{-1-}$ mice, $\mathrm{A} \beta$ injection caused a greater loss of $\mathrm{TH}$-positive neurons in the $\mathrm{SN}$ of $\mathrm{MAC1}^{+/+}$mice than in $\mathrm{MACl}^{-1-}$ mice (Figure 3A). Cell counts revealed a $27 \%$ loss of DA neurons in $\mathrm{MAC1}^{+/+}$controls and $17 \%$ loss in $\mathrm{MAC1}^{-1-}$ mutants (Figure 3C). Thus, deletion of MAC1 protected neurons against microglial activation in vivo.

Microglial morphological changes after $\mathrm{A} \beta$ injection were also examined in the SN (Figure 3B). Microglia were stained with an antibody against Iba1. Resident microglia in both $\mathrm{MACl}^{+/+}$and $\mathrm{MAC1}^{-1-}$ mice express a basal level of Iba1, appear small and bear thin processes. Microglial activation, as demonstrated by a dramatic increase in Iba1 staining, was highly visible in the $\mathrm{SN}$ of $\mathrm{MAC}^{+/+}$mice post-A $\beta$ injection. Numerous microglia assumed a highly activated amoeboid state with an enlarged cell body and thicker cellular processes compared with corresponding saline-injected control sides. $\mathrm{A} \beta$-induced activation of microglia was less pronounced in the $\mathrm{SN}$ of $\mathrm{MAC1}^{-1-}$ mice, which exhibited minimal morphological changes. We also obtained the quantitative changes of Iba- 1 in midbrain area by western blot assay. The results showed elevated Iba- 1 expression in $\mathrm{A} \beta$-treated $\mathrm{MAC1}^{+/+}$mice but not in $\mathrm{MAC1}^{-1-}$ mice (Figure 3D and $3 \mathrm{E}$ ). These in vivo findings confirmed our in vitro result indicating that MAC1 plays a role in $\mathrm{A} \beta$-induced microglial activation and subsequent loss of dopaminergic neurons in the $\mathrm{SN}$.

\section{A $\beta$-induced ROS production from microglia is reduced in $\mathrm{MAC1}^{-/-}$cultures}

We previously showed that microglia enhance $A \beta$ induced toxicity by producing reactive oxygen species, especially extracellular superoxide [6]. To determine the role of MAC1 in $\mathrm{A} \beta$-induced superoxide production,
A
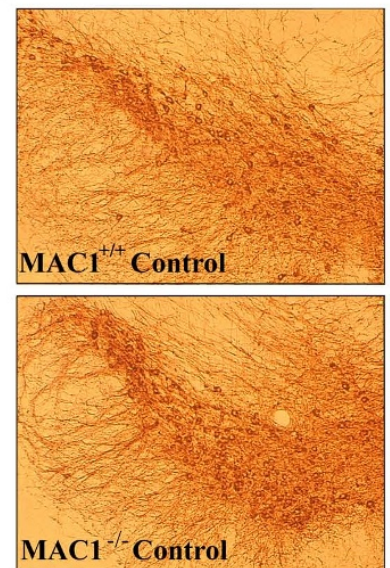

C

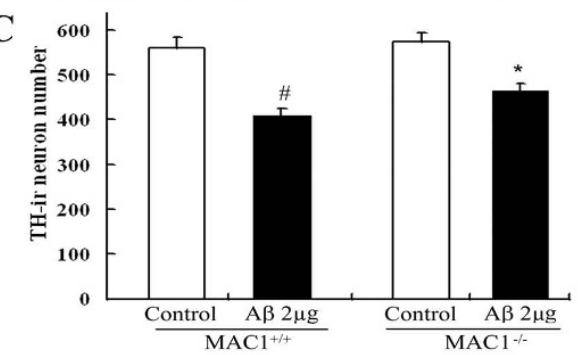

B
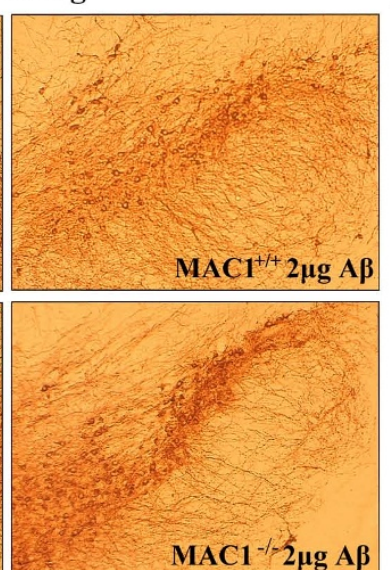
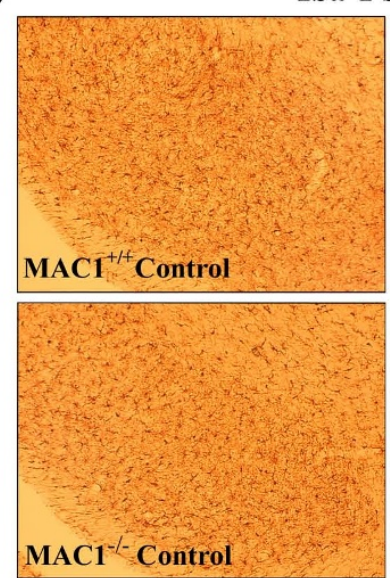

$\mathbf{E}$

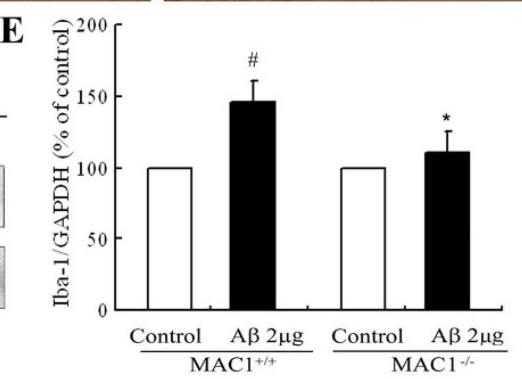

Figure 3 Dopaminergic neurons from MAC1-deficient mice are more resistant to $A \beta$-induced neurotoxicity in vivo. Two $\mu$ g of $A \beta$ were injected into the right side of adult $\mathrm{MACl}^{+/+}$and $\mathrm{MAC1}^{-/-}$mouse SN; vehicle saline alone (control group) was injected into the left side. After 7 days, brains were removed, dopaminergic neurons were stained with an antibody against TH and the microglia were stained with an antibody against Iba-1. Ten animals were used for each group. Dopaminergic neurons were counted in a double-blind manner by three individuals. (A) Immunocytochemical analysis of TH-positive neurons. (B) Number of TH-positive neurons. (C) Immunocytochemical analysis of microglia. (D) Western blot analysis of microglial activation in midbrain area. GAPDH was used as loading control. (E) The ratio of densitometry values of Iba1 and GAPDH was analyzed and normalized to respective control. Results are presented as mean \pm SEM. \#: $p<0.05$ compared with corresponding saline-treated side. *: $\mathrm{p}<0.05$ compared with $\mathrm{MAC1}^{+/+}$mice after same treatments. 
enriched microglial cultures from $\mathrm{MAC1}^{+/+}$and $\mathrm{MAC1}^{-1-}$ mice were exposed to $0.5,1$ and $2 \mu \mathrm{M} \mathrm{A} \beta$ and superoxide production was measured. Figure 4A shows that $A \beta$ increased extracellular superoxide in both cultures. However, the increase was significantly reduced $(\mathrm{P}<0.05)$ in $\mathrm{MAC}^{-/-}$cultures, indicating a role for $\mathrm{MAC1}$ in $\mathrm{A} \beta$-induced superoxide production. To ensure the normal function of PHOX itself in $\mathrm{MACl}^{-1-}$ mice, microglia-enriched cultures from $\mathrm{MAC1}^{+/+}$and $\mathrm{MAC1}^{-1-}$ mice were treated with vehicle, PMA, a potent protein kinase $\mathrm{C}$ agonist that can directly induce the production of superoxide catalyzed by PHOX. Although $A \beta$ induced significantly less production of superoxide in $\mathrm{MAC1}^{-1-}$ microglia compared with that of $\mathrm{MAC1}^{+/+}$ microglia, $\mathrm{MAC1}^{+/+}$and $\mathrm{MAC1}^{-1-}$ microglia demonstrated the same capacity to produce superoxide after PMA, indicating an intact capability for PHOX-mediated superoxide production in these two genotypes. This suggests that the reduced production of superoxide observed in $\mathrm{MAC1}^{-1-}$ neuron-glia cultures after $\mathrm{A} \beta$ exposure cannot be attributed to the malfunction of PHOX.

We also measured intracellular ROS production induced by $A \beta$ using DCFDA. Enriched microglial cells from mice were seeded in dishes at $5 \times 10^{4}$ cells/well and were incubated with $1 \times$ HBSS containing $5 \mu \mathrm{M}$ DCFDA in the dark for 1 hour. Then cells were treated with $\mathrm{A} \beta$ for $10 \mathrm{~min}$. This non-fluorescent compound is oxidized by intracellular ROS to 2,7-dichlorodihydrofluorescein (DCF), which is fluorescent. DCF fluorescence stimulated by $A \beta$ was detected using laser confocal scanning microscopy (Figure 4B). No DCF fluorescence was detected in control cells from both $\mathrm{MAC1}^{+/+}$and $\mathrm{MAC1}^{-1-}$ cultures (Figure 4B I is $\mathrm{MAC1}^{+/+}$control culture and Figure 4B III is $\mathrm{MAC1}^{-1-}$ control culture). A $\beta$ exposure increased DCF fluorescence intensity in both cultures, but the increase in $\mathrm{MAC1}^{-1-}$ cultures was much lower (Figure 4B II and Figure 4B IV are $\mathrm{MAC1}^{+/+}$culture and $\mathrm{MAC1}^{-/-}$culture treated with $A \beta$, respectively.). Thus, MAC1 is closely
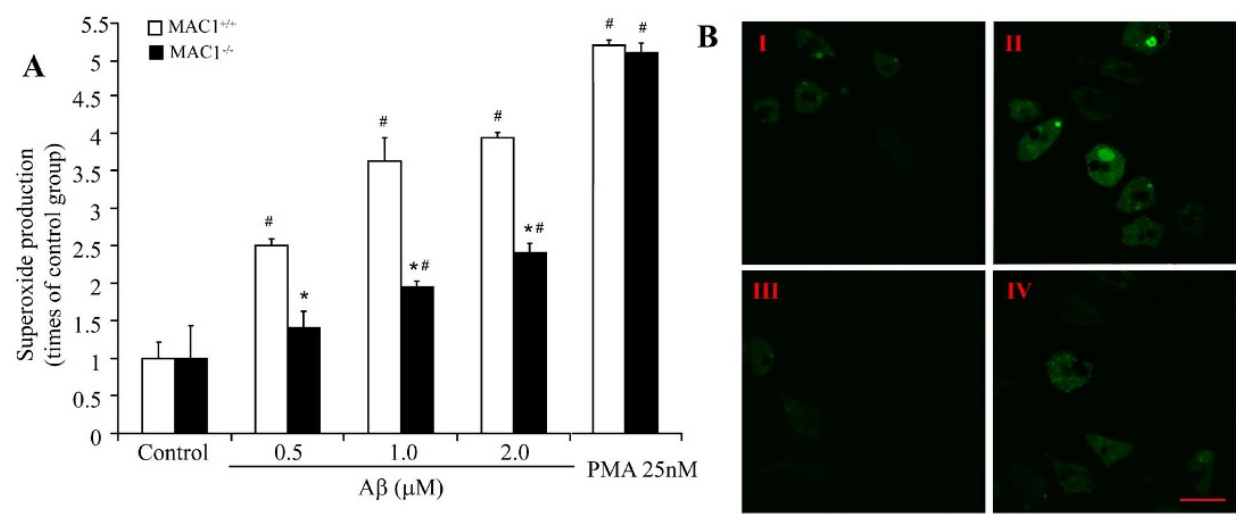

C

D
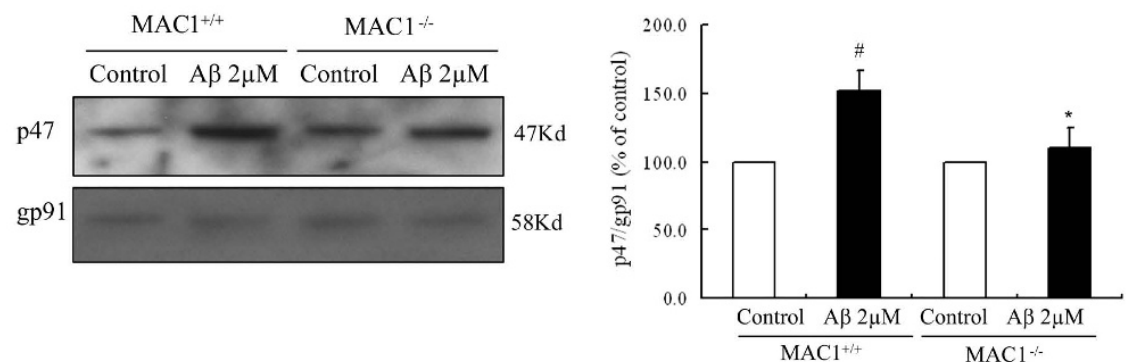

Figure 4 MAC1 mediates activation of PHOX and production of superoxide. (A) Microglia-enriched cultures from MAC1 ${ }^{+/+}$and $\mathrm{MACl}^{-1}$ mice were treated with vehicle medium (control group), A $\beta$ or PMA for 10 min. Extracellular superoxide generation was measured by the SODinhibitable reduction of tetrazolium salt, WST-1. (B) Microglia-enriched cultures from $\mathrm{MACl}^{+/+}$and $\mathrm{MAC1}^{-1-}$ mice were incubated with HBSS containing $5 \mu \mathrm{M}$ DCFDA in the dark for 1 hour. Then cells were treated with vehicle medium (control group) or A $\beta$ for 10 min. Fluorescent images were captured using Zeiss 510 laser scanning confocal microscope. Scale bar: $25 \mu \mathrm{m}$. (C) Western blot assays for p47 $7^{\text {phox }}$ levels in membrane fractions of microglia from $\mathrm{MACl}^{+/+}$and $\mathrm{MAC}^{-1-}$ mice 10 min after vehicle medium (control group) or $A \beta$ treatment. (D) Densitometry analysis was performed with values of $\mathrm{p} 47^{\text {phox }}$ normalized to loading control and further normalized to control levels. Data are presented as mean \pm SEM from three independent experiments. \#: $p<0.05$ relative to corresponding vehicle-treated control cultures. $*: p<0.05$ relative to $\mathrm{MACl}^{+/+}$cultures after same treatments. 
linked with $A \beta$-induced extracellular and intracellular ROS production in microglia.

\section{MAC1 is critical for A $\beta$-induced activation of PHOX and subsequent ROS production after $A \beta$ treatment}

Since extracellular superoxide is an important factor mediating MAC1-enhanced $\mathrm{A} \beta$ neurotoxicity [6] and since PHOX is the key enzyme in extracellular superoxide generation in microglia, we investigated whether PHOX activation depended upon MAC1 expression. Activation of PHOX requires the translocation of cytoplasmic subunits ( $447^{\text {phox }}, \mathrm{p} 67^{\text {phox }}, \mathrm{p} 40^{\text {phox }}$, and Rac) and their subsequent interaction with the membranespanning flavocytochrome b558 [21]. To determine whether MAC1 played a role in PHOX activation, membrane translocation of $\mathrm{p} 47^{\text {phox }}$ was monitored in microglial cultures by western blot following $A \beta$ exposure. We found significantly increased $\mathrm{p} 47^{\text {phox }}$ levels in the membrane fraction of $\mathrm{MAC}^{+/+}$microglia, but not $\mathrm{MAC1}^{-1-}$ microglia 10 minutes after $\mathrm{A} \beta$ exposure (Figure $4 C \& 4 D)$. In contrast, after $A \beta$ exposure, membrane content of $\mathrm{p} 47^{\text {phox }}$ in the $\mathrm{MAC1}^{-1-}$ microglia was substantially reduced. These results suggest the involvement of MAC1 in $\mathrm{p} 47^{\text {phox }}$ membrane translocation and thus PHOX activation induced by $\mathrm{A} \beta$.

\section{$\mathrm{A} \beta$ activates $\mathrm{PHOX}$ via $\mathrm{PI} 3 \mathrm{~K}$ signaling}

A recent study has shown that specific interactions between phox homology (PX) domains and phosphoinositides play a crucial role in the regulation of PXdomain-containing proteins, and has identified the PX domain as a phosphoinositide-binding module involved in cellular signal transduction [22]. We hypothesized that PI3K mediates $A \beta$-induced PHOX activation through the PX domains in two subunits of the NADPH oxidase, $\mathrm{p} 47^{\text {phox }}$ and $\mathrm{p} 40^{\text {phox }}$ [23]. Microglial enriched cultures from $\mathrm{MAC1}^{+/+}$mice were pre-treated with wortmannin, a potent PI3K inhibitor for $30 \mathrm{~min}$ after which the cultures were challenged with $A \beta$. Figure $5 \mathrm{~A}$ shows that wortmannin reduced $A \beta$-induced superoxide production from $\mathrm{MAC1}^{+/+}$microglia in a concentrationdependent manner; wortmannin alone did not alter
A

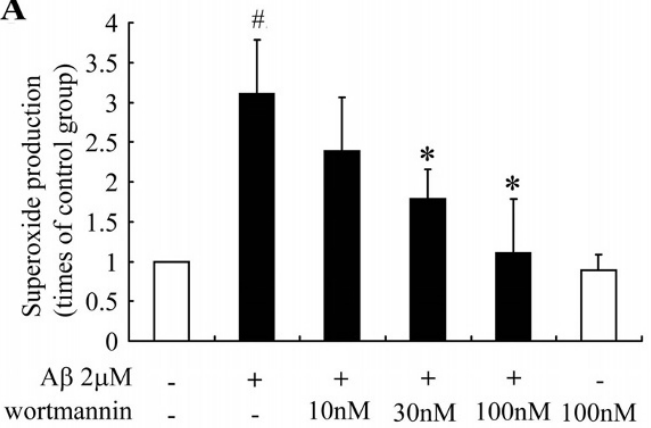

C

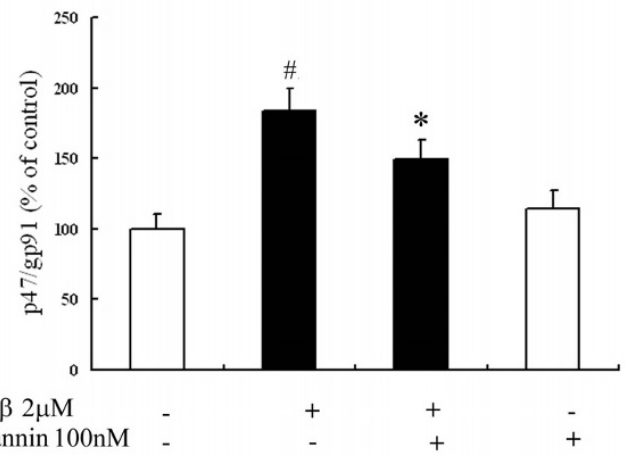

B

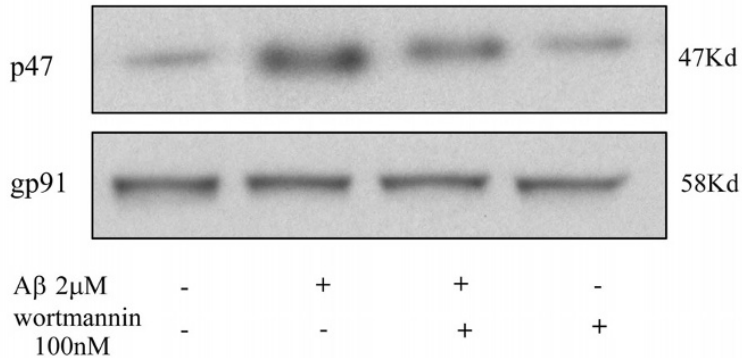

D

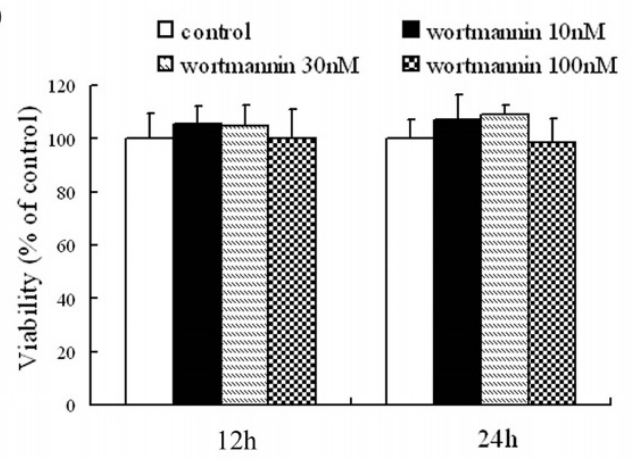

Figure 5 PI3K mediates signaling between MAC1 receptor and PHOX. Microglia-enriched cultures from MAC1 $1^{+/+}$mice were pretreated with wortmannin for $30 \mathrm{~min}$ and then challenged with $A \beta$ for $10 \mathrm{~min}$. (A) Extracellular superoxide generation was measured by the SOD-inhibitable reduction of tetrazolium salt, WST-1. (B) Western blot assays for $p 47^{\text {phox }}$ levels in membrane fractions from microglia. (C) Densitometry analysis was performed with values of $\mathrm{p} 47^{\text {phox }}$ normalized to loading control and further normalized to control levels. (D) Microglia-enriched cultures from $\mathrm{MAC1}^{+/+}$mice were treated with vehicle medium (control group) or different concentrations of wortmannin for 12 or 24 hours; cell viability was measured using MTT assay. Data are presented as mean \pm SEM for three independent experiments. \#: $p<0.05$ relative to vehicletreated control cultures. $*: p<0.05$ relative to $A \beta$-treated cultures. 
superoxide production nor did it induce microglial toxicity (Figure 5D). Western blot analysis showed $100 \mathrm{nM}$ wortmannin significantly inhibited the $A \beta$-induced increase in $\mathrm{p} 47^{\text {phox }}$ levels in the membrane fraction of $\mathrm{MAC1}^{+/+}$cultures (Figure 5B, C), indicating suppression of PHOX activation. These results indicate that PI3K activation is an upstream signal in $\mathrm{A} \beta$-induced PHOX activation in microglia.

\section{MAC1 is necessary for PI3K activation by $A \beta$}

Having demonstrated involvement of PI3K in A $\beta$-induced activation of PHOX, we examined the role of MAC1 in A $\beta$-induced PI3K activation. Translocation of p110 catalytic subunit of type I PI3K to the membrane is required for PI3K activation. Western blots showed that a $10 \mathrm{~min}$
$\mathrm{A} \beta$ exposure of $\mathrm{MAC}^{+/+}$cultures increased the membrane localization of $\mathrm{p} 110$ (Figure 6A). In contrast, $\mathrm{A} \beta$ induced p110 translocation to the membrane was significantly suppressed in $\mathrm{MAC1}^{-1-}$ cultures. Figure $6 \mathrm{~B}$ shows the confocal microscopy results of $\mathrm{PIP}_{3}$ staining before and after $A \beta$ challenge using a monoclonal antibody specific for $\mathrm{PIP}_{3}$, which is a product of activated PI3K. In $\mathrm{MAC}^{+/+}$microglial cultures, $\mathrm{A} \beta$ increased $\mathrm{PIP}_{3}$ staining within $15 \mathrm{~min}$ and the positive staining was localized mainly in the cytoplasm and perinuclear, indicating the activation of PI3K. Similar to the p110 translocation result, $\mathrm{A} \beta$-induced increase in $\mathrm{PIP}_{3}$ staining in $\mathrm{MAC1}^{-/-}$ microglial cultures was much reduced (Figure 6E).

To confirm a role for MAC1 in A $\beta$-induced PI3K activation, we measured activation of PDK1 and AKT, two
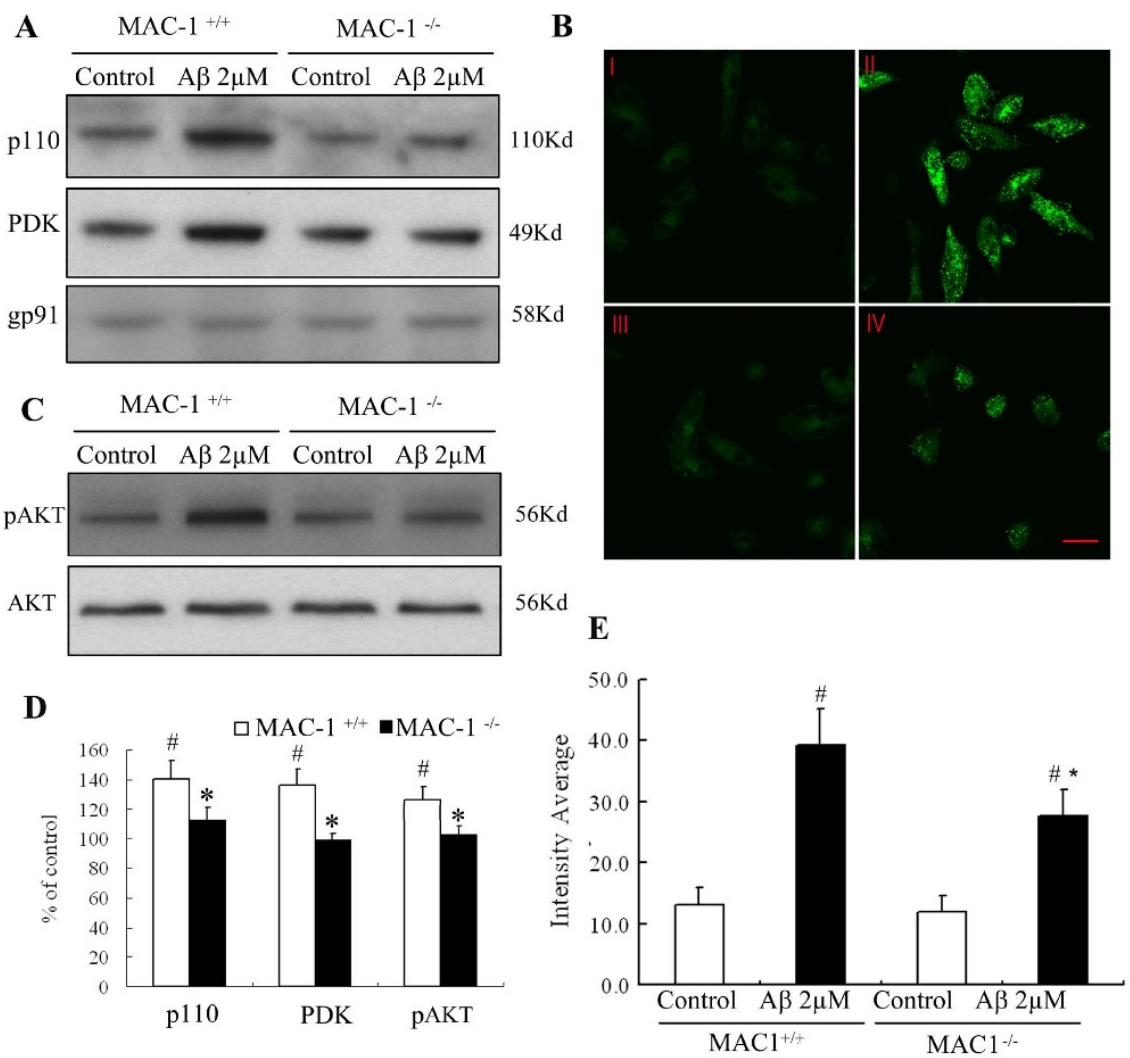

Figure 6 MAC1 is necessary for PI3K activation elicited by $\mathbf{A} \boldsymbol{\beta}$. (A) Western blot assays for p110 and PDK levels in membrane fractions of microglia from $\mathrm{MACl}^{+/+}$and $\mathrm{MAC1}^{-\%}$ mice 10 min after vehicle medium (control group) or A $\beta$ treatment. (B) Enriched microglial cells from

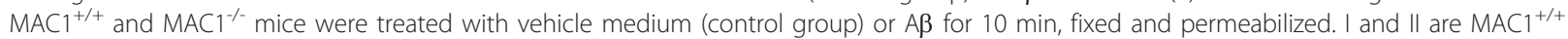
cultures treated with vehicle or $A \beta$, respectively. III and IV are $\mathrm{MAC1}^{-1-}$ cultures treated with vehicle or A $\beta$, respectively. (C) Western blot assays for pAKT and AKT levels in microglia from $\mathrm{MAC1}^{+/+}$and $\mathrm{MAC1}^{-/-}$mice 10 min after vehicle medium (control group) or $\mathrm{A} \beta$ treatment. (D) Densitometry was performed with values normalized to respectively loading control and further normalized to control levels. Cells were incubated with a rabbit polyclonal antibody against $\mathrm{PIP}_{3}$ and then with a FITC-conjugated goat anti-rabbit antibody. Shown are representative confocal images. Scale bar: $25 \mu \mathrm{m}$. (E) Quantitative analysis of the figures in 6B. Average cellular fluorescence was quantitated from at least 100 separate cellular measurements obtained from each treatment group. Background fluorescence, determined in the absence of fluorescence labeled antibody, was minimal in both cell populations (data not shown). Experiments were performed at least three times. \#: $p<0.05$ relative to corresponding vehicle-treated control cultures. ${ }^{*}: \mathrm{p}<0.05$ relative to $\mathrm{MAC1}^{+/+}$cultures after same treatments. 
kinases downstream of PI3K. Activated PI3K produces second messenger $\mathrm{PIP}_{3}$, which binds to the pleckstrin homology domain of PDK1, recruiting it to the plasma membrane where PDK1 is activated by phosphorylation of its activation loop residue $\mathrm{Ser}^{241}$ [22]. A $\beta$ exposure of of $\mathrm{MACl}^{+/+}$microglial cultures induced the phosphorylation of the membrane-associated PDK1 and AKT within $15 \mathrm{~min}$. Significantly less p-PDK and pAKT were found in $\mathrm{MACl}^{-1-}$ microglial cultures (Figure $6 \mathrm{C}$ and $6 \mathrm{D})$. Taken together, these data indicate that MAC1 is upstream of PI3K in A $\beta$-induced activation of microglia.

\section{Discussion}

We demonstrate here that $A \beta$ potently activates microglia in part through the activation of MAC1 receptors, followed by the production of superoxide free radicals, and leading to neuronal death. These results not only confirm our earlier observations that the presence of microglia potentiated the neurotoxicity of $A \beta$, but also reveal several novel findings that illustrated in Figure 7: (1) a role for MAC1 receptor in $A \beta$-induced microglial

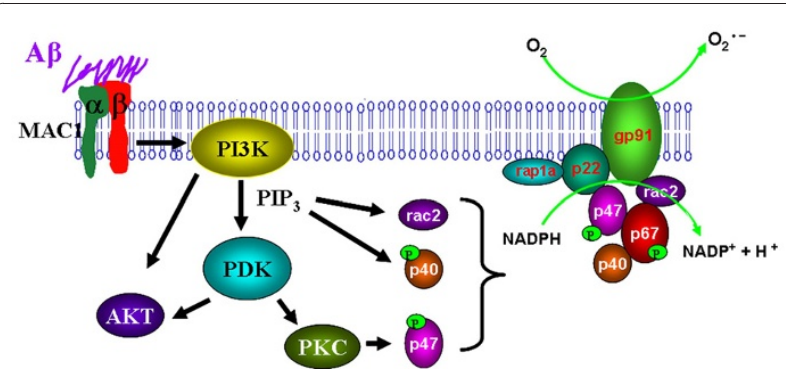

Figure $7 \beta$-amyloid signals through microglial MAC1 receptor and PI3K to PHOX. Microglia exposed to $A \beta$ exhibit a respiratory burst leading to the release of superoxide anion $\left(\mathrm{O}_{2}{ }^{-}\right)$. Release of superoxide is mediated in part through the $A \beta$ cell surface receptor $M A C 1 . A B$ engagement of $M A C 1$ receptor leads to the initiation of complex signaling events mediated by PI3K activation and $\mathrm{PIP}_{3}$ production, which leads to AKT phosphorylation and activation of PDK. Activation of these signaling cascades is linked to the activation of PHOX. PHOX plays an essential role in innate immunity by catalyzing the formation of superoxide. PHOX consists of two integral membrane proteins, $\mathrm{p} 22^{\text {phox }}$ and gp9 phox $^{\text {ph }}$ which together form a heterodimeric flavoprotein known as cytochrome b558. In addition, there are four cytosolic components $\mathrm{p} 47^{\text {phox }}, \mathrm{p} 67^{\text {phox }}$, p40 phox, and the small G-protein Rac. As an important component for PHOX activation, the GDP/GTP exchange on Rac-1 is reported to be a point of possible PI3K intervention. PIP $_{3}$ is reported to bind to $\mathrm{p} 47^{\text {phox }}$ and $\mathrm{p} 40^{\text {phox }}$, and mediates their phosphorylation[46]; PI3K signaling pathway may also sometimes be involved in PKC activation, thus play an important role in the phosphorylation of $p 47^{\text {phox }}$. The cytosolic components then translocate to the membrane where they form a complex with cytochrome b558. The oxidase complex then initiates electron flow and generation of superoxide through the NADPH-derived electron reduction by the flavocytochrome. These findings suggest that MAC1 and PI3K are involved in upstream signaling cascades responsible for activating PHOX assembly and microglia in response to $A \beta$. activation, (2) involvement of MAC1 receptor in PHOX activation which mediates $\mathrm{A} \beta$-induced neurotoxicity and (3) involvement of PI3K in PHOX activation signals by MAC1 receptor.

In the mature brain, microglia are readily activated in response to certain cues such as brain injury or immunological stimuli. Activated microglia serve diverse beneficial functions essential to neuronal survival $[24,25]$. However, with chronic and over-activation, microglia themselves can be detrimentally neurotoxic by excessive production of a large array of cytotoxic factors such as superoxide $[26,27]$. The signals responsible for microglial dysregulation are diverse, ranging from exposure to environmental toxins to neuronal death due to brain damage or genetic diseases.

There has been considerable interest from several laboratories in identifying microglial surface receptors that interact with $A \beta$ fibrils. Scavenger receptor class $A$ (SR-A), scavenger receptor-BI (SR-BI) and CD36 [28-30] El Khoury et al., 1996 J. El Khoury, S.E. Hickman, C.A. Thomas, L. Cao, S.C. Silverstein and J.D. Loike, Scavenger receptor-mediated adhesion of microglia to betaamyloid fibrils, Nat andand and other receptors such as macrophage colony-stimulating factor receptor (MCSF) [31], formyl peptide receptor-1 receptor (FPR-1) [32], receptor for advanced glycation end products (RAGE) [33], etc have been reported to be the binding sites for $A \beta$. A series of papers from Dr. Landreth et al. show that $A \beta$ interacts with a microglial surface receptor complex composed of B-class scavenger receptor CD36, integrinassociated protein/CD47, and $\alpha_{6} \beta_{1}$-integrin [34-37].

MAC1 is a leukocyte integrin expressed on microglia and it is a versatile adhesion and recognition receptor. MAC1 plays a critical role in microglial migration via pathways that include kinase cascades and cytoskeleton rearrangements, culminating in activation critical for antimicrobial leukocyte functions. MAC1 is also reported to cooperatively activate other key adhesion and defense receptors $[38,39]$. In addition to above-mentioned functions, recent work from our laboratory has demonstrated a critical role of MAC1 in mediating the reactivation of microglia in response to neuronal damage/death, socalled reactive microgliosis [17-19]. Our studies suggest that MAC1 serves as a pattern recognition receptor mediating the neurodegeneration produced by toxic substances released from damaged or dead neurons. Since $A \beta$ is one of the constituents in Lewy body, damaged dopaminergic neurons may release $A \beta$ to the extracellular space and further activate microglia at least partially through pattern recognition receptor. Results from this study lend additional support to this possibility.

In the current study, we revealed that MAC1 deficiency mitigated the loss of dopaminergic neurons and GABAergic neurons induced by $A \beta$ exposure, which 
indicates that MAC1 is critical in the $\mathrm{A} \beta$-induced neurotoxic process. MAC1 deficiency did not change the sensitivity of neurons per se because $A \beta$ exerted same degree of toxicity in neuron-enriched cultures from $\mathrm{MAC1}^{-/-}$and $\mathrm{MAC1}^{+/+}$mice. The presence of microglia with functional MAC1 expression was essential for the differential sensitivity to $A \beta$ neurotoxicity. This conclusion is further supported by the lack of robust microglia activation in neuron-glia cultures from $\mathrm{MAC1}^{-1-}$ mice and the in vivo study using $\mathrm{MAC1}^{-1-}$ mice, as measured by changes in cell morphology and by the release of pro-inflammatory factors.

In microglia, activated PHOX is a major source of ROS. Most PHOX products are released into the extracellular space, and it is believed that extracellular ROS plays a major role in neurotoxicity associated with microglial activation [20]. Previous studies in our lab have shown the involvement of PHOX in microglial activation and associated neurotoxicity induced by $A \beta$ [6]. The neurotoxicity observed in cultures from wild type mice that induced by $A \beta$ was potently attenuated in cultures from $\mathrm{PHOX}^{-/-}$mice. Our previous findings, together with present results showing that involvement of MAC1 in $A \beta$-induced neurotoxicity, lend credence to the conclusion that MAC1 receptors are coupled to PHOX for enzymatic activation and subsequent production of superoxide. These conclusions are further supported by the fact that $A \beta$-induced translocation of $\mathrm{p} 47^{\text {phox }}$ from cytosol to cell membrane is substantially diminished in $\mathrm{MAC1}^{-1-}$ cultures. This conclusion is consistent with earlier reports of MAC1-mediated PHOX activation in neutrophils [8] and eosinophils [14].

The next question addressed the signaling pathways mediating the coupling the activation between MAC1 and PHOX. As illustrated in Figure 7, our studies reveal that PI3K is a key mediator for MAC1 to signal the activation of PHOX. PI3K is a class of phosphate kinase that has been implicated in cell signaling pathways that affect cellular death and longevity as well as many other processes that have medically important implications related to disease states [40-42]. The preferred substrate of class I PI3K is phosphoinositide $(4,5)$ bisphosphate $\left(\mathrm{PIP}_{2}\right)$. Phosphorylation of $\mathrm{PIP}_{2}$ by PI3K generates $\mathrm{PIP}_{3}$, which is an important second messenger that can promote cell survival, growth, protein synthesis, mitosis, and motility $[43,44]$. Numerous studies showed that PI3K and $\mathrm{PIP}_{3}$ are involved in the regulation of PHOX. As an important component for PHOX activation, Rac-1 is reported to be a point of possible PI3K intervention [45]. PIP 3 is believed to bind to $\mathrm{p} 47^{\text {phox }}$ and $\mathrm{P}^{\text {phox }} \mathrm{e}^{\text {phox }}$ [46]. PI3K signaling pathway may also be involved in PKC activation, thus play an important role in the phosphorylation of $\mathrm{p} 47^{\text {phox }}[47,48]$. The present results not only show the involvement of PI3K in $A \beta$-induced
PHOX activation, but also suggest that PI3K lies downstream of MAC1 receptor (Figure7).

Although strong evidence from this study illustrates a critical role for MAC1 receptors in mediating $A \beta$-induced neurotoxicity, the inhibition of both dopaminergic neuronal loss and production of superoxide in MAC1-deficient mice or microglia was only partial. These findings indicate that other mechanisms are also involved in A $\beta$-induced effects. In fact, reports from Dr. Landreth's group recently showed that CD14 and Tolllike receptors 2 and 4 are required for fibrillar $A \beta$-stimulated microglial activation [49].

MAC1 has been reported to bind several cell surface and soluble ligands including iC3b, ICAM, fibrinogen, factor X, filamentous hemagglutinin, lipophosphoglycan, and LPS [50,51].12. M. Diamond, J. Garcia-Aguilar, J. Bickford, A. Corbi and T. Springer, The I domain is a major recognition site on the leukocyte integrin Mac-1 for four distinct adhesion ligands. J. Cell Biol. It has been demonstrated that MAC1 is colocalized with $A \beta$ plaques in the brain, thus, it is highly likely that $\mathrm{A} \beta$ activated microglia partly through the binding to MAC1 receptors [52]. To confirm this hypothesis, our ongoing project is to determine if there is direct binding of $A \beta$ to MAC1. Preliminary data from binding assays and immunoprecipitation assays both favor our hypothesis that $\mathrm{A} \beta$ does bind to MAC1 receptors.

In conclusion, results from this study indicate that MAC1 receptor is involved in $A \beta$-induced microglial activation and subsequent neurotoxicity. The present findings are important because they identify an early, possibly initiating, event at the microglial plasma membrane. There are substantial interests in identifying microglial surface molecules that serve in effect as pattern recognition receptors transducing the neurodegenerative effects of substances released from damaged or dead neurons. Interactions involving these putative microglial pattern recognition receptors may represent the initial step in reactive microgliosis, leading to progressive neuronal death in neurodegenerative diseases. In this regard, MAC1 may provide a target for therapeutic intervention. Development of specific MAC1 receptor antagonists may reduce the activation of the MAC1PHOX complex and the subsequent production of proinflammatory factors, extending neuronal survival.

\section{Acknowledgements}

This work was supported by the Intramural Research Program of the National Institutes of Health, National Institute of Environmental Health Sciences. We thank Anthony Lockhart for assistance with animal colony management and maintenance of the timed pregnant mice.

\section{Author details}

${ }^{1}$ Laboratory of Pharmacology, National Institute of Environmental Health Sciences, National Institutes of Health, Research Triangle Park, NC 27709, 
USA. ${ }^{2}$ Institute of Materia Medica, Chinese Academy of Medical Sciences \& Peking Union Medical College, Beijing, 100050, PR China. ${ }^{3}$ Department of Neurology and Pittsburgh Institute of Neurodegenerative Diseases, University of Pittsburgh School of Medicine, Pittsburgh, PA 15261, USA.

${ }^{4}$ Comprehensive Center for Inflammatory Disorders, University of North Carolina, Chapel Hill, NC 27599, USA. ${ }^{5}$ College of Medicine, Institute of Behavioral Medicine, National Cheng-Kung University, Tainan, Taiwan.

\section{Authors' contributions}

DZ performed majority of the experiments and drafted the manuscript. $\mathrm{XMH}, \mathrm{LQ}, \mathrm{SHC}$ and $\mathrm{HZ}$ participated in the experiments. BW carried out the immunostaining assay. DSM and JSH conceived the study and its design and helped to draft the manuscript. All authors read and approved the final manuscript.

\section{Competing interests}

The authors declare that they have no competing interests.

Received: 11 August 2010 Accepted: 13 January 2011

Published: 13 January 2011

\section{References}

1. Arai H, Lee VM, Hill WD, Greenberg BD, Trojanowski JQ: Lewy bodies contain beta-amyloid precursor proteins of Alzheimer's disease. Brain Res 1992, 585:386-390

2. Yoshida T, Ohno-Matsui $K$, Ichinose S, Sato T, Iwata N, Saido TC, Hisatomi T, Mochizuki M, Morita I: The potential role of amyloid beta in the pathogenesis of age-related macular degeneration. J Clin Invest 2005, 115:2793-2800.

3. Jendroska K, Kashiwagi M, Sassoon J, Daniel SE: Amyloid beta-peptide and its relationship with dementia in Lewy body disease. J Neural Transm Supp/ 1997, 51:137-144.

4. Haga S, Akai K, Ishii T: Demonstration of microglial cells in and around senile (neuritic) plaques in the Alzheimer brain. An immunohistochemical study using a novel monoclonal antibody. Acta Neuropathol 1989, 77:569-575.

5. Itagaki S, McGeer PL, Akiyama H, Zhu S, Selkoe D: Relationship of microglia and astrocytes to amyloid deposits of Alzheimer disease. J Neuroimmunol 1989, 24:173-182.

6. Qin L, Liu Y, Cooper C, Liu B, Wilson B, Hong JS: Microglia enhance betaamyloid peptide-induced toxicity in cortical and mesencephalic neurons by producing reactive oxygen species. J Neurochem 2002, 83:973-983.

7. Akiyama H, McGeer PL: Brain microglia constitutively express beta-2 integrins. J Neuroimmunol 1990, 30:81-93.

8. Coxon A, Rieu P, Barkalow FJ, Askari S, Sharpe AH, von Andrian UH, Arnaout MA, Mayadas TN: A novel role for the beta 2 integrin CD11b/ CD18 in neutrophil apoptosis: a homeostatic mechanism in inflammation. Immunity 1996, 5:653-666.

9. Perera PY, Vogel SN, Detore GR, Haziot A, Goyert SM: CD14-dependent and CD14-independent signaling pathways in murine macrophages from normal and CD14 knockout mice stimulated with lipopolysaccharide or taxol. J Immunol 1997, 158:4422-4429.

10. Akiyama H, Tago H, Itagaki S, McGeer PL: Occurrence of diffuse amyloid deposits in the presubicular parvopyramidal layer in Alzheimer's disease. Acta Neuropathol 1990, 79:537-544.

11. Liberatore GT, Jackson-Lewis V, Vukosavic S, Mandir AS, Vila M, McAuliffe WG, Dawson VL, Dawson TM, Przedborski S: Inducible nitric oxide synthase stimulates dopaminergic neurodegeneration in the MPTP model of Parkinson disease. Nat Med 1999, 5:1403-1409.

12. Le Cabec V, Carreno S, Moisand A, Bordier C, Maridonneau-Parini I: Complement receptor 3 (CD11b/CD18) mediates type I and type II phagocytosis during nonopsonic and opsonic phagocytosis, respectively. J Immunol 2002, 169:2003-2009.

13. Ross GD, Vetvicka V: CR3 (CD11b, CD18): a phagocyte and NK cell membrane receptor with multiple ligand specificities and functions. Clin Exp Immunol 1993, 92:181-184.

14. Lynch OT, Giembycz MA, Barnes PJ, Hellewell PG, Lindsay MA: 'Outside-in' signalling mechanisms underlying CD11b/CD18-mediated NADPH oxidase activation in human adherent blood eosinophils. $\mathrm{Br} J$ Pharmacol 1999, 128:1149-1158.
15. Ingalls RR, Arnaout MA, Delude RL, Flaherty S, Savedra R Jr, Golenbock DT: The CD11/CD18 integrins: characterization of three novel LPS signaling receptors. Prog Clin Biol Res 1998, 397:107-117.

16. Medvedev AE, Flo T, Ingalls RR, Golenbock DT, Teti G, Vogel SN, Espevik T: Involvement of CD14 and complement receptors CR3 and CR4 in nuclear factor-kappaB activation and TNF production induced by lipopolysaccharide and group B streptococcal cell walls. J Immunol 1998, 160:4535-4542

17. Hu X, Zhang D, Pang H, Caudle WM, Li Y, Gao H, Liu Y, Qian L, Wilson B, Di Monte DA, et al: Macrophage antigen complex-1 mediates reactive microgliosis and progressive dopaminergic neurodegeneration in the MPTP model of Parkinson's disease. J Immunol 2008, 181:7194-7204.

18. Pei Z, Pang H, Qian L, Yang S, Wang T, Zhang W, Wu X, Dallas S, Wilson B, Reece JM, et al: MAC1 mediates LPS-induced production of superoxide by microglia: the role of pattern recognition receptors in dopaminergic neurotoxicity. Glia 2007, 55:1362-1373.

19. Zhang W, Dallas S, Zhang D, Guo JP, Pang H, Wilson B, Miller DS, Chen B, Zhang W, McGeer PL, et al: Microglial PHOX and Mac-1 are essential to the enhanced dopaminergic neurodegeneration elicited by $\mathrm{A} 30 \mathrm{P}$ and A53T mutant alpha-synuclein. Glia 2007, 55:1178-1188.

20. Gao HM, Liu B, Zhang W, Hong JS: Critical role of microglial NADPH oxidase-derived free radicals in the in vitro MPTP model of Parkinson's disease. Faseb J 2003, 17:1954-1956.

21. Babior BM: NADPH oxidase: an update. Blood 1999, 93:1464-1476.

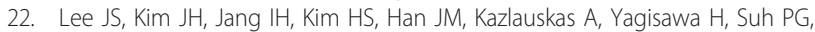
Ryu SH: Phosphatidylinositol $(3,4,5)$-trisphosphate specifically interacts with the phox homology domain of phospholipase D1 and stimulates its activity. J Cell Sci 2005, 118:4405-4413.

23. Zhan Y, Virbasius JV, Song X, Pomerleau DP, Zhou GW: The p40phox and p47phox PX domains of NADPH oxidase target cell membranes via direct and indirect recruitment by phosphoinositides. J Biol Chem 2002, 277:4512-4518

24. Streit WJ: Microglia as neuroprotective, immunocompetent cells of the CNS. Glia 2002, 40:133-139.

25. Town T, Nikolic $V$, Tan J: The microglial "activation" continuum: from innate to adaptive responses. J Neuroinflammation 2005, 2:24.

26. Lee SC, Liu W, Dickson DW, Brosnan CF, Berman JW: Cytokine production by human fetal microglia and astrocytes. Differential induction by lipopolysaccharide and IL-1 beta. J Immunol 1993, 150:2659-2667.

27. Block ML, Zecca L, Hong JS: Microglia-mediated neurotoxicity: uncovering the molecular mechanisms. Nat Rev Neurosci 2007, 8:57-69.

28. El Khoury J, Hickman SE, Thomas CA, Cao L, Silverstein SC, Loike JD: Scavenger receptor-mediated adhesion of microglia to beta-amyloid fibrils. Nature 1996, 382:716-719.

29. Husemann J, Loike JD, Anankov R, Febbraio M, Silverstein SC: Scavenger receptors in neurobiology and neuropathology: their role on microglia and other cells of the nervous system. Glia 2002, 40:195-205.

30. Paresce DM, Ghosh RN, Maxfield FR: Microglial cells internalize aggregates of the Alzheimer's disease amyloid beta-protein via a scavenger receptor. Neuron 1996, 17:553-565.

31. Mitrasinovic OM, Murphy GM Jr: Accelerated phagocytosis of amyloidbeta by mouse and human microglia overexpressing the macrophage colony-stimulating factor receptor. J Biol Chem 2002, 277:29889-29896.

32. Le Y, Gong W, Tiffany HL, Tumanov A, Nedospasov S, Shen W, Dunlop NM, Gao JL, Murphy PM, Oppenheim JJ, Wang JM: Amyloid (beta)42 activates a G-protein-coupled chemoattractant receptor, FPR-like-1. J Neurosci 2001, 21:RC123.

33. Yan SD, Chen X, Fu J, Chen M, Zhu H, Roher A, Slattery T, Zhao L, Nagashima M, Morser J, et al: RAGE and amyloid-beta peptide neurotoxicity in Alzheimer's disease. Nature 1996, 382:685-691.

34. Bamberger ME, Harris ME, McDonald DR, Husemann J, Landreth GE: A cell surface receptor complex for fibrillar beta-amyloid mediates microglial activation. J Neurosci 2003, 23:2665-2674.

35. Bamberger ME, Landreth GE: Microglial interaction with beta-amyloid: implications for the pathogenesis of Alzheimer's disease. Microsc Res Tech 2001, 54:59-70.

36. Koenigsknecht J, Landreth G: Microglial phagocytosis of fibrillar betaamyloid through a beta1 integrin-dependent mechanism. J Neurosci 2004, 24:9838-9846. 
37. Wilkinson B, Koenigsknecht-Talboo J, Grommes C, Lee CY, Landreth G Fibrillar beta-amyloid-stimulated intracellular signaling cascades require Vav for induction of respiratory burst and phagocytosis in monocytes and microglia. J Biol Chem 2006, 281:20842-20850.

38. Gahmberg CG, Tolvanen M, Kotovuori P: Leukocyte adhesion-structure and function of human leukocyte beta2-integrins and their cellular ligands. Eur J Biochem 1997, 245:215-232.

39. Plow EF, Zhang L: A MAC-1 attack: integrin functions directly challenged in knockout mice. J Clin Invest 1997, 99:1145-1146.

40. Brachmann SM, Yballe CM, Innocenti M, Deane JA, Fruman DA, Thomas SM, Cantley LC: Role of phosphoinositide 3-kinase regulatory isoforms in development and actin rearrangement. Mol Cell Biol 2005, 25:2593-2606.

41. Katso R, Okkenhaug K, Ahmadi K, White S, Timms J, Waterfield MD: Cellular function of phosphoinositide 3-kinases: implications for development, homeostasis, and cancer. Annu Rev Cell Dev Biol 2001, 17:615-675.

42. Vanhaesebroeck B, Waterfield MD: Signaling by distinct classes of phosphoinositide 3-kinases. Exp Cell Res 1999, 253:239-254.

43. Deane JA, Fruman DA: Phosphoinositide 3-kinase: diverse roles in immune cell activation. Annu Rev Immunol 2004, 22:563-598.

44. Cantrell DA: Phosphoinositide 3-kinase signalling pathways. I Cell Sci 2001, 114:1439-1445

45. Welch HC, Coadwell WJ, Stephens LR, Hawkins PT: Phosphoinositide 3kinase-dependent activation of Rac. FEBS Lett 2003, 546:93-97.

46. Perisic O, Wilson Ml, Karathanassis D, Bravo J, Pacold ME, Ellson CD, Hawkins PT, Stephens L, Williams RL: The role of phosphoinositides and phosphorylation in regulation of NADPH oxidase. Adv Enzyme Regul 2004, 44:279-298.

47. Cross AR, Segal AW: The NADPH oxidase of professional phagocytesprototype of the NOX electron transport chain systems. Biochim Biophys Acta 2004, 1657:1-22.

48. Sheppard FR, Kelher MR, Moore EE, McLaughlin NJ, Banerjee A, Silliman CC: Structural organization of the neutrophil NADPH oxidase: phosphorylation and translocation during priming and activation. J Leukoc Biol 2005, 78:1025-1042.

49. Reed-Geaghan EG, Savage JC, Hise AG, Landreth GE: CD14 and toll-like receptors 2 and 4 are required for fibrillar A\{beta\}-stimulated microglial activation. J Neurosci 2009, 29:11982-11992.

50. Ehlers MR: CR3: a general purpose adhesion-recognition receptor essential for innate immunity. Microbes Infect 2000, 2:289-294.

51. Newham P, Humphries MJ: Integrin adhesion receptors: structure, function and implications for biomedicine. Mol Med Today 1996, 2:304-313.

52. Strohmeyer R, Ramirez M, Cole GJ, Mueller K, Rogers J: Association of factor $\mathrm{H}$ of the alternative pathway of complement with agrin and complement receptor 3 in the Alzheimer's disease brain. J Neuroimmunol 2002, 131:135-146.

doi:10.1186/1742-2094-8-3

Cite this article as: Zhang et al:: Microglial MAC1 receptor and PI3K are essential in mediating $\beta$-amyloid peptide-induced microglial activation and subsequent neurotoxicity. Journal of Neuroinflammation 2011 8:3.

\section{Submit your next manuscript to BioMed Central and take full advantage of:}

- Convenient online submission

- Thorough peer review

- No space constraints or color figure charges

- Immediate publication on acceptance

- Inclusion in PubMed, CAS, Scopus and Google Scholar

- Research which is freely available for redistribution

Submit your manuscript at www.biomedcentral.com/submit
Biomed Central 